\title{
Research on Effective Managing Method of Human Resources Using Value Engineering
}

\author{
Heungjae Cho ${ }^{1, a}$, Jaeil Park ${ }^{1, b, *}$ \\ ${ }^{1}$ College of engineering, Ajou University, Suwon City, South Korea \\ adeadposo@gmail.com, bjipark@ajou.ac.kr \\ ${ }^{*}$ Corresponding author
}

Keywords: Value engineering, Similarity, Re-arranging.

\begin{abstract}
The effort to reduce the processing cost is required to secure the company's competitiveness. In order to reduce the process cost by reducing the work generated in the process is a necessary for a method that can be used effectively to personnel. In this study, by confirming the similarity and the location and required skill of the work, proposed a method for the integration or re-arranging easily. In order to assess the similarity of work, by applying the function analysis method R. B. Stone has presented, and check whether the delete or integration is possible for work. Using the working location and required skills, presents a re-arranging method between other works.

We presented efficiently personnel rearranged case of the melting, chip melting process and the melted aluminum supply process in aluminum wheel plant. By the suggested method, it is expected that it can be to facilitate relocation efficient personnel to reduce the process costs.
\end{abstract}

\section{Introduction}

Through process analysis, in advance, companies removed factors of problems of process, and reduce the lead time in developing production plan, promptly. Also it is needed to reduce the cost of production of products to ensure the improvement and competitiveness of enterprises of productivity. It is necessary to struggle to reduce waste and defective element for the competitiveness [1]. The manufacturing process in each company, it consists of repetitive process and less repeatability processes. Repetitive process is as the work at the conveyor line or the union work with equipment. Irregular process means the work which assists the repetitive process or the valuable works such as prepare replacement work. As a way to improve the repetitive process, there are a variety of things such as line balancing, man machine chart etc. These techniques have already been procedural. However, improvement of the irregular process is still not easy. Therefore, there is a need for an efficient management method of personnel through the improvement of irregular operation [2].

In this study, it is determined whether or not that can delete or integrate the work or process using the similarity between tasks. And also, we present a method to re-arrange the work through the working location. In addition, we present the analysis method using the time for efficiency measurement of personnel. We used VE (value engineering) to understand the similarity of the work, which is mainly used for analysis of functional analysis of products.

RB Stone presents the eight function class and three flow class that can be used easily for of functional analysis [3].

In this study, we changed three flow classes to suit to the manufacturing process. Also, we presented a re-arrangement method of work by constituting the working time of the worker's and the working range of worker.

Rest of this paper is organized as follows. Section 2 presents the theoretical background of value engineering, R. B. Stone's research and Design for assembly. Section 3 presents the proposed method and section 4 presents the case study. Section 5 shows the conclusion of this paper. 


\section{Literature review}

\section{Function definition and heuristic method of Stone}

Stone used three flow classes and eight function classes when defining the function. Three flows classes, which are material, signal and energy, are equivalent to the noun part during the function definition. Eight function classes, which are grouped as the branch, channel, connect, control magnitude, convert, provision, signal and support, are the verb part of the function [4]. Using this method, it is possible to perform the function definition easily and quickly. Stone also proposed a heuristic method to modulate the function. The first is dominant flow, second is branching flow and the third is convert transmit flow as table 1.

Tab. 1 Heuristic method to modulate functions

Dominant flow

\section{Research method}

1. Identify the possibilities of elimination or combination of operations

2. Identify the possibilities of re-arrangement among operations

3. Confirm the possibilities of working time

4. Derive possible number of workers

The effective management of personnel is not made through the reduction of personnel, only. It should be able to perform all of the existing work in small groups. However, reduction of the personnel is to result in an increase in working time. Therefore, first, the reduction of the working time should be performed through the analysis of the job deletion and integration of an existing work. Then, the method by the relocation of an operation that will reduce the personnel, without increasing the operation time is required. Finally, we check the working time after improvement to confirm the possibilities work time and possible number of workers.

Identify the possibilities of elimination or combination of operations. Before confirming the possibility of deleting integration tasks, we perform the work analysis to derive the works. In order to reduce the working time, the operations should be deleted, and integrated. We used a table that has been deformed in accordance with the operation of the three flow class and eight function classes which are used in method of R. B. Stone, and this is the heuristic method, especially, dominant flow. In this study, we used the material names that are put directly into process. Also machine class is used to show that what tools or equipment are used to perform the operation. Since the material and machine which are used in each plant is limited, it is possible to change the term to be used depending on the case. Table 2 is an example for checking similarity by confirming 3 classes.

Tab. 2 Similarity of process or work

\begin{tabular}{|l|l|l|l|l|}
\hline Work & Material & machine & function & similarity \\
\hline A & Solid & Hand & Move & A-B: similar \\
\hline B & Solid & jig & Move & C: Not similar \\
\hline C & Liquid & hand & Prevent & \\
\hline
\end{tabular}

Method of deriving a working similarity is as follows. If the flow class and the machine class, either function class matches, it shall be deemed to have similarities between tasks. Since, it is possible to present a method to incorporate the operation. If two abnormal matches in three classes, it is possible to find a possible integration proposed improvements more easily. For example, the operation of moving the 
aluminum ingot with a crane and moving the aluminum ingot with hand, Improvement point is to find a method capable of transferring the aluminum ingot at a time.

Identify the possibilities of re-arrangement among operations. Also, to maximize the efficiency of the personnel, it can be achieved through even relocation operations of different processes. To understand the Re-arrange possibilities between steps, it is necessary to consider the working skill level and workers working radius. When it is needed to relocate working, connection relationships between the process, the operator's skill level should be considered. It is also considered whether or not the other operator can easily perform the operation. If the work does not require special tool and if the operation is simple, then the other operator can perform the work. We can confirm the possibility of relocation process through Table 4. In this case, the position of a generated in the peripheral equipment ' $b$ ' of an operator and the operation ' $\mathrm{A}$ ' is due to the low rating can be done by the operator in charge of the plant, ' $\mathrm{b}$ '. However, task B cannot be performed by other workers, since they require a high degree of technology and there is any equipment or operator, near task B.

Confirm the possibilities of working time and Derive possible number of workers.

$$
y=\frac{\sum x_{j} \times y_{i}}{n}
$$

$\mathrm{y}=$ Expected number of workers after improvement

$\mathrm{xi}=$ Work time of each worker after improvement

yi=Number of workers before improvement

$\mathrm{n}=$ Operating hours for one day per worker

After the improvement, work time and the number of workers could be confirmed by the equation 1 . If the work time is not possible, then the number of workers should increase than existing workers, however, if the work time is suitable, then the number of workers should be less than existing.

\section{Case study}

Case studies presented in this study, is improving work of melting, chip melting process and hot water supplying process of alloy wheel manufacturing factory, especially, the melting, chip melting and supplying melted aluminum to casting machine.

Melting process is consisted of flux treatment, removing slag and Ingot loading operations, and this operation is less repetitive. And chip melting process is consisted of flux treatment, removing slag and verifying the chips that melt well. Supplying process involves degassing process and supplying melted aluminum to the casting machine

For the improvement of each process, first, the work analysis was performed as table 3.

Tab. 3 Work analysis of melting and chip melting process

\begin{tabular}{|l|l|l|l|l|l|}
\hline $\begin{array}{l}\text { Melting } \\
\text { Process }\end{array}$ & Operation & $\begin{array}{l}\text { Work time } \\
\text { (sec/1day) }\end{array}$ & $\begin{array}{l}\text { Chip melting } \\
\text { process }\end{array}$ & Operation & $\begin{array}{l}\text { Work time } \\
\text { (sec/day) }\end{array}$ \\
\hline $\begin{array}{l}\text { Transmit } \\
\text { Ingot bundles }\end{array}$ & Move & 1800 & $\begin{array}{l}\text { Start conveyor } \\
\text { line }\end{array}$ & Operation active & 300 \\
\hline $\begin{array}{l}\text { Check } \\
\text { melting row }\end{array}$ & Investigation & 3000 & $\begin{array}{l}\text { Check melting } \\
\text { row }\end{array}$ & Investigation & 1800 \\
\hline $\begin{array}{l}\text { Move to the } \\
\text { gate }\end{array}$ & Move & 800 & Move to gate & Move & 400 \\
\hline $\begin{array}{l}\text { Flux } \\
\text { treatment }\end{array}$ & $\begin{array}{l}\text { Operation } \\
\text { active }\end{array}$ & 1200 & Flux treatment & Operation active & 1000 \\
\hline
\end{tabular}

To combine or delete the work unit, we checked the similarity of machine, material and function class. Table 4 shows an example that for melting process. 
Tab. 4 Checking the similarity of each work unit

\begin{tabular}{|l|l|l|l|l|l|l|l|l|l|}
\hline No. & Work unit & material & machine & function & No. & $\begin{array}{l}\text { Work } \\
\text { unit }\end{array}$ & material & machine & Function \\
\hline 1 & $\begin{array}{l}\text { Move } \\
\text { ingot } \\
\text { bundle }\end{array}$ & Ingot & $\begin{array}{l}\text { Forklift } \\
\text { truck }\end{array}$ & Move & 5 & $\begin{array}{l}\text { Separate } \\
\text { ingot } \\
\text { bundle }\end{array}$ & Ingot & Hoist & Separate \\
\hline 2 & $\begin{array}{l}\text { Eliminate } \\
\text { bend }\end{array}$ & Bend & Knife & Eliminate & 6 & $\begin{array}{l}\text { Fix hoist } \\
\text { and ingot } \\
\text { bundle }\end{array}$ & Ingot & Hoist & Move \\
\hline 3 & $\begin{array}{l}\text { Ingot } \\
\text { re-position }\end{array}$ & Ingot & Hoist & Move & 7 & $\begin{array}{l}\text { Load } \\
\text { ingot on } \\
\text { conveyor }\end{array}$ & Ingot & Hoist & Move \\
\hline 4 & $\begin{array}{l}\text { Separate } \\
\text { two ingot } \\
\text { peace }\end{array}$ & Ingot & Hand & Separate & & & & & \\
\hline
\end{tabular}

As table 4, the similarity of each work unit was confirmed by the 3 classes. At here, the work unit No. 4 and No. 5 could be combined because of the similarity of material class and function class. In addition, because of the similarity of all classes, work unit number 5 and 6 could be combined by improvement suggestions. As like this, about $16500 \mathrm{sec}, 19000 \mathrm{sec}$ and $20000 \mathrm{sec}$ could be improved by this logic.

To check the re arrangement of each process, the location and skill of the process should be checked as table 5 .

Tab. 5 Possibility of work re-arranging

\begin{tabular}{|l|l|l|l|}
\hline Process & Work unit & location & Skill \\
\hline \multirow{3}{*}{$\begin{array}{l}\text { Supply } \\
\text { melted }\end{array}$} & Transmit ladle to the Melting row & Chip melting & High(drive folklift truck) \\
\cline { 2 - 4 } & Open gate & Chip melting & Low \\
\cline { 2 - 4 } & Flow melted aluminum & Chip melting & Low \\
\cline { 2 - 4 } & Wait & Chip melting & Low \\
\cline { 2 - 4 } & Close gate & Chip melting & Low \\
\cline { 2 - 4 } & Move ladle from the melting row & Chip melting & High(drive folklift truck) \\
\hline
\end{tabular}

As table 5, such work unit as opening gate, flowing melted aluminum and closing gate could be performed by the worker of chip melting. It is also same not only between melting process and chip melting process, but also between melting process and supplying melted aluminum process. Because of the re-arranging, it was possible to manage human resource effectively.

The effectiveness is checked by equation 1 . And the result was that the 3 process is available to handle by only 1.9 workers.

\section{Conclusion}

In this study, using a value engineering techniques, we proposed for efficient personnel operating the way through deletion / consolidation and relocation of operations.

By applying the method of Stone for products, we used in the work process to determine the action proposed a standard similarity to the delete / integration operations. In addition, by proposed re-arranging method, the effective personal management could be performed. The idea for improvement can be identified of each work unit or process, through the proposed method. Therefore, it is possible to focus at the ideas for improvement of cost competitiveness without wasting time. In future study, the research for the more detail rules of deleting / integrating and re-arranging the works are necessary.

\section{References}

[1] Miles, L. D. "VALUE ANALYSIS AND ENGINEERING." New York-Toronto-London (1961). 
[2] Tohidi, H. (2011). Review the benefits of using value engineering in information technology project management. Procedia Computer Science, 3, 917-924.

[3] Stone, R. B., Wood, K. L., \& Crawford, R. H. (2000). A heuristic method for identifying modules for product architectures. Design studies, 21(1), 5-31.

[4] Stone, R. B., Wood, K. L., \& Crawford, R. H. (1998, September). A heuristic method to identify modules from a functional description of a product. In Proceedings of DETC98 (pp. 1-11).J. van der Geer, J.A.J. Hanraads, R.A. Lupton, The art of writing a scientific article, J. Sci. Commun. 163 (2000) 51-59. 